\title{
Optimalisasi Proses Manufaktur dalam Pembuatan Pipa Union dengan Menggunakan Metode Hungarian dan PERT/CPM
}

\section{Optimization of Manufacturing Process in Union Pipe Using Hungarian Method and PERT/CPM}

\author{
Rianita Puspa Sari ${ }^{1 *}$, Okky Jayadi ${ }^{2}$, Langgam Tandya Nugraha ${ }^{3}$ \\ ${ }^{1,2,3}$ Program Studi Teknik Industri, Universitas Singaperbangsa Karawang, J1. H. S. Ronggowaluyo, \\ Telukjambe Timur, Karawang 41361, Indonesia
}

Diterima: 24 Januari 2018; Direvisi: 6 Februari 2018; Disetujui: 8 Februari 2018

\begin{abstract}
ABSTRAK
CV. Faresti Prima yang merupakan perusahaan yang bergerak dibidang machining, automatic part, dies and jigs. Unit Pipa Union merupakan bagian yang diteliti, dikarenakan memiliki permasalahan dibagian penugasan yang masih manual. Pengambilan data dilakukan pada unit pipa union dengan rata-rata kerja per hari. Permasalahan yang ada terdapat pada unit pipa union dengan penugasan secara manual. Pengamatan yang dilakukan terhadap 4 orang untuk pekerjaan memotong pipa, chamfering, stamping, dan packing. Hasil pengamatan kemudian dilakukan pengolahan data dengan menggunakan metode Hungarian, sehingga didapatkan unit optimum yang dihasilkan per jam sebanyak 8,125. Selanjutnya, dilakukan pengolahan data dengan menggunakan Metode PERT dengan hasilnya menyatakan bahwa urutan pengerjaan optimum adalah A-B-C-D-E dengan jumlah waktu pengerjaan untuk 5,000 unit selama 16.5 jam. Pengolahan data terakhir dengan menggunakan Metode CPM dapat diketahui bahwa terjadi percepatan waktu sebanyak 8 jam dari waktu awal adalah 16.5 jam dengan total biaya crash sebesar Rp 4,000,000 dari dana yang alokasikan sebesar Rp 4,225,000. Dari beberapa pengolahan data tersebut dapat diketahui bahwa terjadi optimasi dalam penugasan dan jaringan kerja. Oleh karena itu, sesuai dengan teori yang ada dan tujuan dari penelitian ini, yaitu untuk mengoptimalkan SDM yang ada agar pekerjaan dilakukan secara merata dan meminimasi kerugian akibat menganggur penggunaan metode tersebut dapat dijadikan sebagai acuan dalam pembuatan jadwal, sehingga dapat mempermudah jalannya proyek untuk mengetahui keterlambatan dalam setiap prosesnya.
\end{abstract}

Kata Kunci: Optimasi, Metode Hungarian, PERT, CPM

\begin{abstract}
CV. Faresti Prima which is a company engaged in machining, automatic part, dies, and jigs. Union Pipe Unit is part of the research because it has problems in the assignment that is still manual. Data collection is done on unit union pipe with average work per day. The problem is found in the union pipe unit with the manual assignment. Observations made on 4 people for cutting pipes, chamfering, stamping, and packing. Results of observations then performed data processing using Hungarian method, so that the optimum unit is generated per hour as much as 8.125. Furthermore, data processing was performed using PERT method with the result stated that the optimum working order was A-B-C-D-E with total processing time for 5,000 units for 16.5 hours. The last data processing using CPM method can be seen that the acceleration time as much as 8 hours from the initial time is 16.5 hours with the total crash cost of 4,000,000 IDR from the allocated fund of 4,225,000 IDR. From some data processing, it can be seen that there is an optimization in the assignment and network work. Therefore, in accordance with the existing theories and objectives of this research, namely to optimize the existing human resources for the work done equally and minimize the losses due to unemployed use of these methods can be used as a reference in the making of the schedule, so as to facilitate the course of the project to know the delay in every process.
\end{abstract}

Keywords: Optimization, Hungarian Method, PERT, CPM

*e-mail: rianita.puspasari@ft.unsika.ac.id 


\section{PENDAHULUAN}

\subsection{Latar Belakang}

Menyelesaikan proyek tepat waktu dan sesuai anggaran bukan tugas yang mudah. Terlepas dari kemajuan di bidang manajemen proyek saat ini, kebanyakan proyek saat ini menghadapi biaya dan waktu yang meningkat seiring dengan meningkatnya kompleksitas proyek yang terlibat. Sejumlah besar faktor berkontribusi terhadap penundaan yang terutama disebabkan oleh penundaan kontraktor, keterlambatan klien, penundaan konsultan, penundaan terkait tenaga kerja, dan berbagai penundaan eksternal lainnya. Keterlambatan ini dalam jangka panjang menyebabkan waktu berlipat, biaya berlebihan, perselisihan, arbitrase, pengabaian dan litigasi total. Hal ini karena beberapa kegiatan proyek sangat penting dalam arti bahwa keterlambatan dalam permulaan akan menunda keseluruhan waktu penyelesaian proyek. Oleh karena itu, perencanaan, dan penjadwalan proyek yang tepat penting untuk mengatasi masalah ini. Sebuah proyek dapat didefinisikan sebagai seperangkat sejumlah besar kegiatan atau pekerjaan yang dilakukan dalam urutan tertentu yang ditentukan secara logis atau teknologis dan harus diselesaikan dalam waktu dan biaya yang ditentukan sambil memenuhi standar kinerja. Proyek ini bisa berupa pengembangan program perangkat lunak, pembangunan rumah atau gedung perkantoran, pengembangan obat baru, kampanye pemasaran untuk produk baru, dan banyak lainnya (Agyei, 2015).

Permasalahan yang dihadapi oleh perusahaan yang diteliti adalah penugasan yang masih manual di unit pipa union. Oleh karena itu, perlunya pengoptimalan masalah penugasan dan analisis jaringan kerja dengan menggunakan metode Hungarian dan PERTCPM.

Metode Hungarian merupakan suatu masalah-masalah yang berhubungan dengan lokasi optimal dari berbagai macam sumber daya yang produktif, terutama tenaga kerja atau personalia, yang mempunyai tingkat efisiensi berbeda-beda untuk pekerjaan yang berbeda-beda pula. Masalah ini disebut masalah penugasan (assignment problem), yang merupakan suatu kasus khusus dari masalah linear programming pada umumnya. Metode ini mula-mula dikembangkan oleh seorang ahli matematika berkebangsaan Hungarian yang bernama D. Koing pada tahun 1916 (Handoko, 2000). Metode Hungarian merupakan metode yang memecahkan masalah matematika dalam penelitian operasional dalam masalah penugasan (Kuhn, 2012).

Analisis jaringan kerja adalah cara konvensional untuk menemukan cara yang paling terampil untuk menghubungkan sejumlah aktivitas secara langsung atau tidak langsung untuk memenuhi persyaratan penawaran dan permintaan di lokasi aktivitas dan penjadwalan proyek yang berbeda. Selama bertahun-tahun, dua pendekatan yang telah terbukti berguna untuk perencanaan, penjadwalan dan pengendalian proyek adalah PERT dan CPM (Agyei, 2015).

Penjadwalan sebuah proyek dapat disajikan dengan grafik yang dapat mengambil sejumlah arti tertentu, tergantung pada metode yang digunakan. Terdapat dua metode yang sangat banyak digunakan: Program Evaluation and Review Technique Critical Path Method (PERT - CPM) (Réveillac, 2015).

Metode CPM adalah metode untuk merencanakan dan mengawasi proyekproyek merupakan yang paling banyak dipergunakan diantara yang lainnya dengan memakai prinsip pembentukan jaringan (Levin dan Kirkpatrick, 1972). Dengan metode CPM, jumlah waktu yang dibutuhkan untuk menyelesaikan berbagai tahap suatu proyek dianggap diketahui dengan pasti, demikian pula hubungan antara sumber yang digunakan dan waktu yang diperlukan untuk menyelesaikan proyek.

Penelitian ini dilakukan untuk mengoptimalkan penugasan yang ada agar pekerjaan dapat dilakukan secara merata dan meminimasi kerugian akibat adanya pekerja yang menanggur. Kontribusi yang diharapkan adalah penggunaan metode Hungarian, PERT, dan CPM dapat dijadikan sebagai acuan dalam pembuatan jadwal, sehingga dapat mempermudah jalannya proyek untuk mengetahui keterlambatan dalam setiap prosesnya, sehingga dapat mengatasi permasalahan tersebut. 


\subsection{Ruang Lingkup Penelitian}

Penelitian dilakukan pada CV. Faresti Prima yang merupakan perusahaan yang bergerak dibidang Machining, Automatic Part, Dies and Jigs. Unit Pipa Union merupakan bagian yang diteliti, dikarenakan memiliki permasalahan dibagian penugasan yang masih manual. Pengambilan data dilakukan pada unit pipa union dengan ratarata kerja per hari.

\section{METODOLOGI}

CV. Faresti Prima merupakan perusahaan yang bergerak dibidang Machining, Automatic Part, Dies and Jigs, salah satu produknya adalah pipa union pada Gambar1.

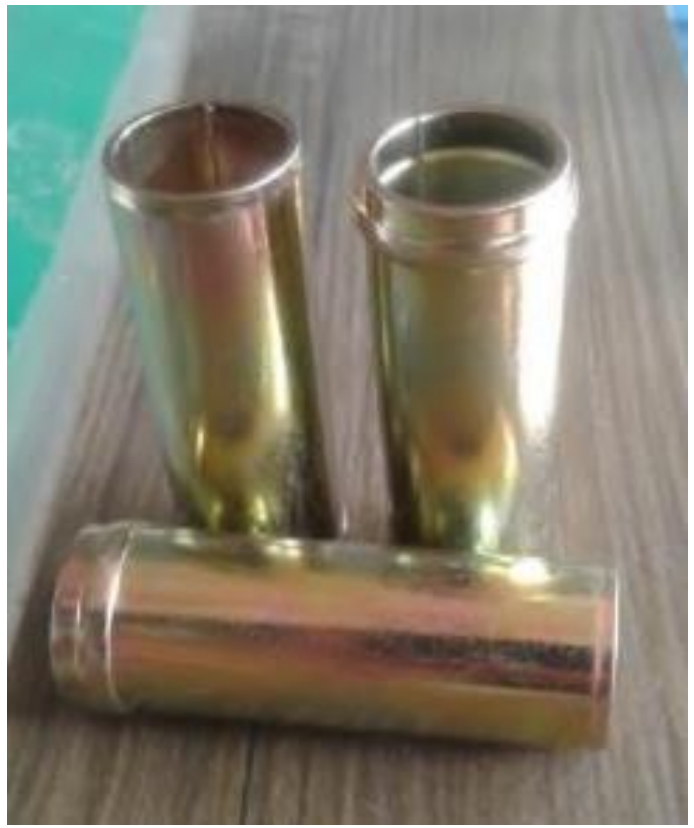

Gambar 1. Produk Pipa Union

Tahapan untuk memproduksi Pipa Union seperti Gambar 1. adalah pemotongan pipa, chamfering, stamping, plating dan packing. Tahapan plating tidak diteliti karena dilakukan secara subkontrak. Data diperoleh terhadap 4 orang dari masing-masing pekerjaan. Sebagai acuan dalam mempermudah penelitian dan proses pengumpulan data, maka langkah-langkah yang dilakukan dapat dilihat pada Gambar 2.

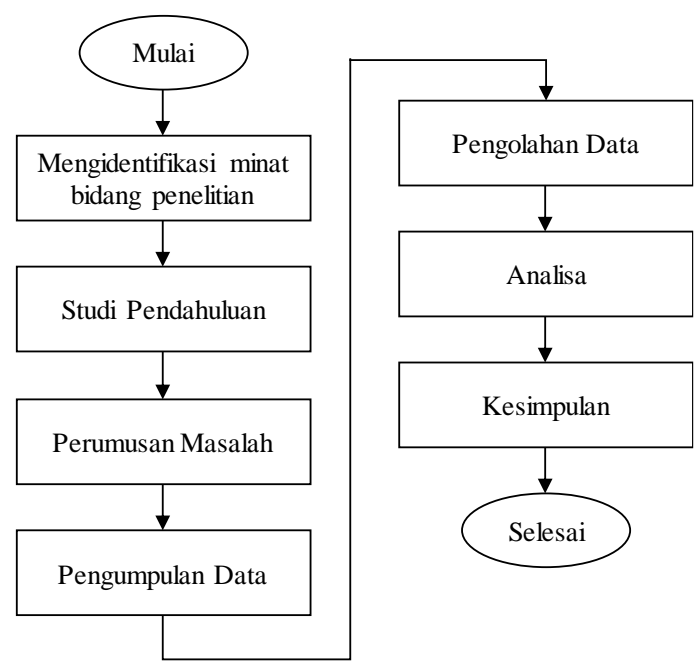

Gambar 2. Langkah-langkah Pelaksanan Penelitian

\section{HASIL DAN PEMBAHASAN}

\subsection{Metode Hungarian}

Permasalahan yang ada terdapat pada unit pipa union dengan penugasan secara manual. Pada Tabel 1. merupakan hasil pengamatan yang dilakukan terhadap 4 orang untuk pekerjaan memotong pipa, chamfering, stamping, dan packing. Penyelesaian untuk kasus tersebut untuk mencari kondisi optimal penugasan pekerja agar total waktu pekerjaan dapat diminimukan dengan mencari selisih nilai dengan nilai terbesar di setiap baris, sehingga didapatkan Tabel 2.

$$
\operatorname{Min} Z=\sum_{i=1}^{n} \sum_{j=1}^{n} C_{i j} X_{i j}
$$

Subject to:

$$
\begin{array}{ll}
\sum_{i=1}^{m} X_{i j}=1 & \text { untuk } i=1,2,3, \ldots, n \\
\sum_{j=1}^{n} X_{i j}=1 & \text { untuk } j=1,2,3, \ldots, n \\
X_{i j} \geq 0 & \text { untuk semua } i \text { dan } j
\end{array}
$$

dimana:

$Z \quad$ : Fungsi tujuan

$X_{i j}:$ Variabel keputusan 
$C_{i j} \quad$ : Nilai kontribusi objek $i$ terhadap tugas $j$

$m$ : Jumlah objek (individu tau sumber daya)

$n$ : Jumlah tugas/pekerjaan yang akan diselesaikan

$i \quad$ : Pekerja

$j \quad$ : Pekerjaan

Tabel 1. Data Penugasan 4 Karyawan dalam Unit/Jam

\begin{tabular}{lcccc}
\hline \multirow{2}{*}{ Pekerjaan } & $\mathbf{1}$ & $\mathbf{2}$ & $\mathbf{3}$ & $\mathbf{4}$ \\
\hline Memotong & 1,800 & 1,850 & 1,825 & 1,810 \\
Pipa & & & & \\
Chamfering & 750 & 720 & 730 & 710 \\
Stamping & 1,850 & 1,830 & 1,875 & 1,800 \\
Packing & 3,600 & 3,500 & 3,620 & 3,650 \\
\hline
\end{tabular}

Sumber: Hasil Pengamatan (2017)

Tabel 2. Pengolahan Data Penugasan 4 Karyawan

\begin{tabular}{lcccc}
\multicolumn{1}{c}{ Pekerjaan } & $\mathbf{1}$ & $\mathbf{2}$ & $\mathbf{3}$ & $\mathbf{4}$ \\
\hline Memotong Pipa & 50 & 0 & 25 & 40 \\
Chamfering & -0 & 30 & 20 & 40 \\
Stamping & 25 & 45 & 0 & 75 \\
Packing & 50 & 0 & 30 & 0 \\
\hline
\end{tabular}

Sumber: Pengolahan Data (2018)

Berdasarkan dari Tabel 2. dapat diketahui bahwa jumlah garis yang dilalui oleh 0 sama dengan jumlah baris/kolom, sehingga pemecahan sudah optimal. Pekerja 1 ditugaskan untuk melakukan chamfering 750 unit/jam, pekerja 2 ditugaskan untuk memotong pipa 1,850 unit/jam, pekerja 3 ditugaskan untuk melakukan stamping 1,875 unit/jam, dan pekerja 4 ditugaskan untuk melakukan packing 3,650 unit/jam, sehingga didapatkan unit optimum yang dihasilkan per jam sebanyak 8,125.

\subsection{PERT}

Berdasarkan alokasi waktu dan kegiatan proyek pada Tabel 4. maka dapat dilanjutkan ke tahap pembuatan diagram proyek perencanaan jaringan kerja dapat dilihat pada Gambar 3. dan perhitungannya yang dapat dilihat pada Tabel 5 .

Nilai-nilai yang tertera pada diagram jaringan kerja tersebut dihitung sebagai berikut:

\section{a. Earliest Time (ET)}

Rumus: $(T E)_{b}=(T E)_{a}+L$

Keterangan:

$a \quad$ : kejadian awal kegiatan $x$

$b \quad:$ kejadian akhir kegiatan $x$

$(T E)_{a}:$ saat kejadian awal

$(T E)_{b}$ : saat kejadian akhir

$L \quad$ : waktu kegiatan

b. $\quad$ Latest Time (LT)

Rumus: $(T L)_{a}=(T L)_{b}-L$

Keterangan:

$a \quad$ : kejadian awal kegiatan $x$

$b \quad:$ kejadian akhir kegiatan $x$

$(T L)_{a}$ : saat kejadian awal

$(T L)_{b}$ : saat kejadian akhir

$L \quad$ : waktu kegiatan

Dengan demikian, dapat dihitung besar TE dan TL yang dapat dilihat di Tabel 5. Hasil dari metode PERT menyatakan bahwa urutan pengerjaan optimum adalah A-B-C-D$\mathrm{E}$ dengan jumlah waktu pengerjaan untuk 5,000 unit selama 16.5 jam.

\subsection{CPM}

Hasil perhitungan dari Metode PERT didapatkan jumlah waktu yang dibutuhkan untuk pengerjaan 5,000 unit adalah selama 16.5 jam, dikarenakan perusahaan memiliki alokasi dana sebesar $\mathrm{Rp} \mathrm{4,225,000} \mathrm{untuk}$ 5,000 unit maka dilakukan perhitungan lanjutan dengan Metode CPM agar alokasi dana terpenuhi dan waktu pengerjaan dapat dipercepat. Crashing per periode waktu dapat dicari dengan menggunakan data waktu dan biaya crash pada Tabel 3. dengan persamaan (5).

$$
\text { Crashing per waktu }=\frac{C C-N C}{N T-C T}
$$

dimana:

$C C$ : Biaya akselerasi (crash cost)

NC: Biaya normal (normal cost)

$N T$ : Waktu normal (normal time)

$C T$ : Waktu akselerasi (crash time)

Dengan demikian didapatkan crashing/jam seperti pada Tabel 6. Crashing ke-1 dengan selisih waktu 4 jam maka waktu penyelesaian menjadi $16,5-4=12,5$ jam 
dengan total biaya ditambah Rp 50,000 menjadi Rp 3,200,000. Crashing ke-2 dengan selisih waktu 1 jam maka waktu penyelesaian menjadi $12,5-1=11,5$ jam dengan total biaya ditambah $\mathrm{Rp} 200,000$ menjadi $\mathrm{Rp}$ 3,400,000. Crashing ke-3 dengan selisih waktu 1 jam maka waktu penyelesaian menjadi $11,5-1=10,5$ jam dengan total biaya ditambah $\mathrm{Rp} 200,000$ menjadi $\mathrm{Rp}$
3,600,000. Crashing ke-4 dengan selisih waktu 1 jam maka waktu penyelesaian menjadi $10,5-1=9,5$ jam dengan total biaya ditambah Rp 200,000 menjadi Rp 3,800,000. Crashing ke-5 dengan selisih waktu 1 jam maka waktu penyelesaian menjadi 9,5 - 1= 8,5 jam dengan total biaya ditambah dari $\mathrm{Rp}$ 200,000 menjadi Rp 4,000,000.

Tabel 3. Waktu dan Biaya Crash

\begin{tabular}{cccccc}
\hline \multirow{2}{*}{ No. } & \multirow{2}{*}{ Kegiatan } & \multicolumn{2}{c}{ Waktu (Jam) } & \multicolumn{2}{c}{ Biaya (Rp) } \\
& & Normal & Crash & Normal & Crash \\
\hline 1 & A & 7 & 3 & 750,000 & 950,000 \\
2 & B & 3 & 2 & 500,000 & 700,000 \\
3 & C & 3 & 2 & 750,000 & 950,000 \\
4 & D & 2 & 1 & $1,000,000$ & $1,200,000$ \\
5 & E & 1.5 & 0.5 & 150,000 & 350,000 \\
\hline
\end{tabular}

Sumber: Pengolahan Data (2018)

Tabel 4. Uraian Kegiatan

\begin{tabular}{ccccc}
\hline No. & Kegiatan & Uraian Kegiatan & Kegiatan Sebelumnya & Waktu Normal (Jam) \\
\hline 1 & A & Memotong Pipa & - & 7 \\
2 & B & Chamfering & A & 3 \\
3 & C & Stamping & B & 3 \\
4 & D & Plating & C & 2 \\
5 & E & Packing & D & 1.5 \\
\hline
\end{tabular}

Sumber: Pengolahan Data (2018)

\subsection{Analisis Jaringan Kerja}

Berdasarkan pengolahan data pada metode Hungarian mengenai penugasan maka peneliti menghitung waktu yang dibutuhkan pekerja untuk menyelesaikan masing-masing 5,000 unit pada masing- masing pengerjaan dengan mengumpulkan data tambahan berupa jumlah waktu crash dan biaya $\mathrm{crash} / \mathrm{jam}$ sebesar Rp 4,225,000. Data waktu dan biaya crash disajikan pada Tabel 3. dan uraian kegiatan disajikan pada Tabel 4.

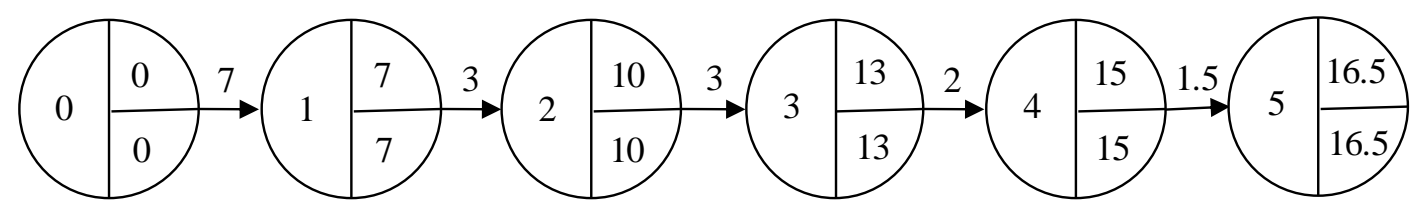

Gambar 3. Diagram Proyek Perencanaan Jaringan Kerja

Tabel 5. Pengolahan Data Metode PERT

\begin{tabular}{cccccc}
\hline No. & Kegiatan & Kegiatan Sebelumnya & Normal & TE & TL \\
\hline 1 & A & - & 7 & 7 & 7 \\
2 & B & A & 3 & 3 & 3 \\
3 & C & B & 3 & 3 & 3 \\
4 & D & C & 2 & 2 & 2 \\
5 & E & D & 1.5 & 1.5 & 1.5 \\
\hline
\end{tabular}

Sumber: Pengolahan Data (2018) 


\begin{tabular}{lr}
\hline \hline Versi online: & Journal of Industrial Engineering and Management Systems \\
http://journal.ubm.ac.id/index.php/jiems & Vol. 11, No. 1, 1-6, 2018 \\
DOI: dx.doi.org/10.30813/jiems.v11i1.1010 & ISSN 1979-1720 \\
Hasil Penelitian & E-ISSN 2579-8154 \\
\hline \hline
\end{tabular}

Tabel 6. Biaya Crashing/Jam

\begin{tabular}{ccccccc}
\hline \multirow{2}{*}{ No. } & \multirow{2}{*}{ Kegiatan } & \multicolumn{2}{c}{ Waktu (Jam) } & \multicolumn{2}{c}{ Biaya (Rp) } & \multirow{2}{*}{ Normashing/Jam } \\
\hline 1 & A & 7 & Crash & Normal & Crash & Cras \\
2 & B & 3 & 2 & 750,000 & 950,000 & 50,000 \\
3 & C & 3 & 2 & 700,000 & 700,000 & 200,000 \\
4 & D & 2 & 1 & $1,000,000$ & $1,200,000$ & 200,000 \\
5 & E & 1.5 & 0.5 & 150,000 & 350,000 & 200,000 \\
\hline
\end{tabular}

Sumber: Pengolahan Data (2018)

\section{KESIMPULAN}

Dari pengolahan data yang sudah dilakukan dapat diambil kesimpulan bahwa dengan menggunakan metode Hungarian, PERT dan CPM dapat mengatasi permasalahan yang dihadapi oleh perusahaan. Metode Hungarian dalam penugasan dapat mengetahui penugasan dari masing-masing kerja secara optimal. Pekerja 1 ditugaskan untuk melakukan chamfering 750 unit/jam, pekerja 2 ditugaskan untuk memotong pipa 1,850 unit/jam, pekerja 3 ditugaskan untuk melakukan stamping 1,875 unit/jam, dan pekerja 4 ditugaskan untuk melakukan packing 3,650 unit/jam, sehingga didapatkan unit optimum yang dihasilkan per jam sebanyak 8,125.

Metode PERT menyatakan bahwa urutan pengerjaan optimum adalah A-B-C-D$\mathrm{E}$ dengan jumlah waktu pengerjaan untuk 5.000 unit selama 16.5 jam. Berdasarkan pengolahan data pada Metode CPM dapat diketahui bahwa terjadi percepatan waktu sebanyak 8 jam dari waktu awal adalah 16.5 jam dengan total biaya crash sebesar Rp $4,000,000$ dari dana yang alokasikan sebesar Rp 4,225,000.

\section{DAFTAR PUSTAKA}

Agyei, W. (2015) "Project Planning and Scheduling Using PERT and CPM Techniques with Linear Programming: Case Study," International Journal of Scientific \& Technology Research, 4(8), hal. 222-227.

Handoko, T. H. (2000) Dasar-dasar Manajemen Produksi dan Operasi. 1 ed. Yogyakarta: BPFE. Kuhn, H. W. (2012) "A Tale of Three Eras: The Discovery and Rediscovery of The Hungarian Model," European Journal of Operationnal Research, 219, hal. 641-651.

Levin, R. I. dan Kirkpatrick, C. A. (1972) Perencanaan dan Pengawasan dengan PERT dan CPM. Jakarta: Bhratara.

Réveillac, J.-M. (2015) Optimization Tools for Logistics. 1 ed, Optimization Tools for Logistics. 1 ed. London: ISTE Press Ltd. 